\title{
Article
}

\section{Coping Strategies in the Family and School Ecosystem}

\author{
Cristina Sánchez-Romero ${ }^{1, * \mathbb{C}}$, Eva María Muñoz-Jiménez ${ }^{2}$, Isabel Martínez-Sánchez ${ }^{3} \mathbb{C}$ and \\ María del Carmen López-Berlanga ${ }^{4}$
}

1 Department of Didactics, School Organization and Special Teaching, Faculty of Education, National Distance Education University (UNED), 28040 Madrid, Spain

2 International Doctoral School, Faculty of Education, National Distance Education University (UNED), 28040 Madrid, Spain; emunoz324@alumno.uned.es

3 Department of Research Methods and Educational Diagnosis I, Faculty of Education, National Distance Education University (UNED), 28040 Madrid, Spain; imsanchez@edu.uned.es

4 López Vicuña Primary School, 28037 Madrid, Spain; maricarmen@lopezvicu.es

* Correspondence: csanchez@edu.uned.es

Received: 13 July 2020; Accepted: 25 July 2020; Published: 29 July 2020

\begin{abstract}
The objective of the present study is to study children's coping strategies used when faced with different stressors in their daily life (problems with their school work, problems getting along with other children and problems at home with people in their family), in a vulnerable social environment. This objective was evaluated through the Child Coping Questionnaire. The research for this study was conducted through a descriptive, inferential, quantitative, ex post facto design. The sample consisted of 50 schoolchildren from one suburban primary school in Madrid, Spain. The ages of the children range from 8 to 11 years. At present, almost $25 \%$ families are in a vulnerable situation. This instrument measures 14 coping categories that analyse positive and self-effective attitudes to favour socio-communicative processes and decision-making in situations of conflict between students. The results indicate that what bothers children the most is, first of all, problems getting along with other children (35.8\%), problems with their school work $(30.2 \%)$ and problems at home with people in their family (24.5\%). Regarding their lifestyle outside the school environment and relationship with their family, 38\% of participants spend a lot of time outside their home, according to our findings. This result can explain the difficulties in completing their homework that these children have. This can also trigger a curricular gap compared to their reference group, which can sometimes lead to school failure.
\end{abstract}

Keywords: coping strategy; family; school; vulnerability; curricular gap

\section{Introduction}

During early childhood, children begin to deal with a new set of problems; in this way they learn to manage positive and negative emotions in a socially appropriate way. Indeed, children that live in a vulnerable social environment add to these coping problems their family context. This context is perceived as a stressor factor for children at risk and in a position of social vulnerability; this factor has an influence on the acquisition of children's coping strategies.

Different studies have been carried out on coping strategies in different contexts, and there is a continuous discussion about their applicability in different backgrounds. These studies show that they can be exclusion and marginalization strategies for low-income families [1]. Moreover, studies in contexts of coping with violence show that the coping of caregivers and the family context contribute to how children face violence [2]. So, the application of these strategies of coping must take into account the changing environment [3]. Other studies [4] show us the effectiveness of the coping strategies of 
children who live in parental vulnerability settings, such as avoidance and distraction as a protective factor against depression and physical and psychological health problems.

As far as coping strategies during childhood are concerned, this refers to the way in which the subject tries to adapt activities to the situation [5]. Dual-process models defined coping as "regulation under stress establishing links to the development of emotion, attention, behavioural self-regulation and suggest constitutional underpinnings and social factors that shape coping development" [6]. There are two types of coping, it can be adaptive or maladaptive. Coping is adaptive when the alterations allow the individual to adapt better to environmental conditions. However, coping is maladaptive when there is a more unfavourable environmental adjustment and may affect the integrity of the person. On the one hand, children's coping strategies are focused on the problem, emotions, primary control, secondary control and approach, all these are related to better psychological adjustment. On the other hand, maladaptive coping strategies, such as self-guilt, rumination, catastrophism, aggression and avoidance are related to unhealthy psychological adjustment $[7,8]$.

In relation to this, children adjust their coping strategies to the type of stressor they experience, for example, socially excluded children are more likely to exhibit internal coping and physical victims are more likely to show external coping [9-14].

When a child is faced with a stressful event, such as a peer conflict or school failure, a variety of emotional and motivational reactions lead to different types of coping response [15]. The coping focuses on how multiple subsystems (emotional, behavioural, motivational, attention, cognitive and social processes) work together to cope with stress. The coping style is a mixture of attributive style (source of perceived stress, control locus, optimistic or pessimistic perspective to find a solution) and personality characteristics, such as risk tolerance, sense of self-efficacy, and introversion or extroversion. Coping strategies reflect the repertoire of stress responses that children are able to successfully use. Coping strategies can be explicitly taught through models, while personality is relatively fixed.

Most studies on coping mechanisms coincide in determining three domains of coping strategies as they are aimed at valuation (cognitive coping: attempt to find a more positive meaning to the event and assess it in a way that is less unpleasant), at the problem (behavioural coping: behaviour aimed at finding solutions, anticipating and managing its consequences) and emotion (emotional coping: regulation of emotional aspects and attempt to maintain emotional balance in the situation that generates conflict) [16]. Therefore, cognitive resources, controlled emotional processes and effective behaviours are necessary for effective coping with problems or situations that generate tension. The review of 44 studies that report coping and coping strategies from childhood to adolescence identified the 12 coping strategies used most frequently: search for support (sometimes covering the search for information or seeking help); cognitive and/or behavioural escape; cognitive and/or behavioural distraction; problem-solving and instrumental action; accommodation (e.g., acceptance); opposition (for example, blaming others); denial of self-sufficiency (for example, accepting responsibility for solving the problem; self-regulation of emotions); social isolation aggression (for example, social withdrawal and avoiding others); negotiation (for example, negotiation and priority setting); impotence (for example, confusion); and positive cognitive revaluation [11].

The search for a coping structure can be based on families through family ties and adaptive processes. The application of coping strategies to reduce stress in families showed the need for resources to cope with stressful situations.

The school selected for the study is located in the South district of Madrid. The population of this district is characterized by a high percentage of families of a foreign origin, long-term unemployment and low incomes. The current population demographic is mostly Latin Americans: Ecuadorians $(29.79 \%)$, Colombians $(12.55 \%)$, Peruvians $(5.64 \%)$ and Bolivians $(3.94 \%)$. There are also families from other origins such as Romanians or Moroccans.

The percentage of families in this district that have temporary work is $20.7 \%$, which represents a high level of vulnerability and high risk of social exclusion. Indeed, social services work with these families to improve their well-being and ensure families receive the help they need; some of them 
receive the GMI (guaranteed minimum income), but others do not receive any kind of economic support, which makes them more vulnerable to possible situations of marginalization and risk of social exclusion. This study was carried out with a sample of vulnerable children who need strategies to cope with adverse social, cultural and economic circumstances. This study looks into the children's problems in acquiring coping strategies in contexts where their family and other peers are in vulnerable situations [17].

The criteria that we consulted for our study was based on [8], who analysed 58 coping studies with more than 250 age correlations, analysed and highlighted among other "developmental patterns" of coping with a focus on changes occurring with age (e.g., problem-solving, distraction, seeking support, escaping), with a focus on the age changes that reflect increases in coping capacity: seeking support (from adult dependence to greater self-sufficiency), problem solving (from instrumental action to planned problem solving) and distraction (adding cognitive strategies to behavioural strategies).

\section{Methods}

The research for this study was conducted through a descriptive, inferential, quantitative, ex post facto design [18].

Therefore, an existing instrument was chosen, which measures those aspects of children's coping. In addition, the following variables were analysed in this study: gender, age, children's worrying situations and the way in which they face these situations.

The purpose of this study was to determinate children's reasons for anger or feeling bad and their ability to handle these situations. To achieve this objective, the difference in gender (boys and girls) was analysed in the different items through descriptive analyses. According to the recommendations of Ruiz, Pardo, and San Martín [19], a normality test was carried out, verifying the normality assumption. The normality assumption assumes that the data were sampled from populations having normal distributions. The normality test was calculated by both test statistics (Kolmogórov-Smirnov and Shapiro-Wilk tests) and editing the graph box plot graphics.

\subsection{Participants}

The sample was selected through non-probability sampling, allowing us to select those accessible cases that agreed to be included in the study. Thus, it was considered the characteristic feature of the families (the high level of vulnerability), due to the fact that most of the families receive support from Social Affairs, City Council and care centres in order to improve their wellbeing. A total of 50 children took part in the survey with a range of ages from 8 to 11 years old. By gender, the percentages of the participants were $52 \%$ girls and $48 \%$ boys. The children's age groups are outlined in Table 1 :

Table 1. Sample description.

\begin{tabular}{ccc}
\hline Children's Age Groups & Percentage & Accumulated Percentage \\
\hline 8 & 6.0 & 6.0 \\
9 & 6.0 & 12.0 \\
10 & 40.0 & 52.0 \\
11 & 48.0 & 100.0 \\
Total & 100.0 & \\
\hline
\end{tabular}

The sample consisted of 50 schoolchildren from one suburban primary school in Madrid, Spain. The ages of the children ranged from 8 to 11 years. At present, almost $25 \%$ of families are in a vulnerable situation, and they have support from the GMI, Social Services, the City Council and the Family Care Centre, as we described previously. These children can use two approaches to their emotions and attitudes (positive or negative) in relation to aggression and related avoidance as an unhealthy psychological adjustment in order to manage this environment [20,21]. A first approach assumes that the student's attitudes and emotions towards others are negative when faced with stressful situations, 
such as a conflict between peers or family, leading to different types of responses (releasing their feelings and emotions or not). In both cases they would be vulnerable students; if they release their feelings and emotions and confront each other, they can be used for this type of confrontation as well as being used by a leader. However, if they do not release their feelings and are submissive, they are simply more vulnerable than others and can become victims of any kind of conflict.

Regarding their lifestyle outside the school environment and the relationship with their family, a total of $38 \%$ participants spend a lot of time outside their home, according to our findings. This result can explain the difficulties in completing their homework that these children have. Moreover, this can trigger a curricular gap compared to their reference group, which can sometimes lead to school failure.

\subsection{Instrument}

The Children's Coping Questionnaire (CCQ) is a comprehensive survey of 81 questions to assess the coping capacity of school-age children [22]. The CCQ evaluates 14 conceptually different coping strategies: cognitive decision making, direct problem solving, self-calming, avoidance actions, cognitive avoidance, distracting actions, no coping actions, retention of feelings, expression of feelings, negative cognitions/worrying, aggressive actions, illusions, positive cognitive support, seeking support. Children are asked to answer questions about these 14 coping categories, using four points on a Likert scale: Score 1 (never), Score 2 (a little), Score 3 (much) and Score 4 (a lot). In addition, the internal consistency reliability of this questionnaire was measured by Cronbach's alpha with a range between 0.56 and 0.85 .

\subsection{Procedure}

In first place, we needed to have access to families with specific characteristics for the study. For this, we contacted with the Department of Education, which had previously spoken with the families to inform them about the research and request their collaboration on a voluntary basis. When the research methodology was described, and the information of the families that accepted to participate were obtained, a first contact was made to them through a phone call, to later personally meet them and explain the goal of the investigation and give them clear instructions for the correct application of the questionnaire.

After that, the data were collected, the answers were coded, arranged and computerized in a database for subsequent statistical treatment. Then, the analysis of the quantitative results was carried out through the statistical analysis program SPSS.

\section{Results}

A complete descriptive analysis of the questions was carried out, using contingency table techniques. It should be noted that we chose the distribution chi-squared test to see if there is significant differences between boys and girls. Regarding each question asked, we calculated the contingency coefficient, which allows us to differentiate between boys' and girls' opinions and their correlation.

According to their age and gender, the reasons why children are 'upset or bothered by things', are shown in Table 2:

Table 2. Reasons why children are 'upset or bothered by things' based on their age and gender.

\begin{tabular}{ccccccc}
\hline \multirow{2}{*}{ Gender } & \multicolumn{3}{c}{ How Old Are You? } & \multicolumn{2}{c}{ Total } \\
& & $\mathbf{8}$ & $\mathbf{9}$ & $\mathbf{1 0}$ & $\mathbf{1 1}$ & \\
\hline \multirow{4}{*}{ Girl } & Problems with you school work. & $4.0 \%$ & $0.0 \%$ & $12.0 \%$ & $8.0 \%$ & $24.0 \%$ \\
& Problems getting along with other kids. & $0.0 \%$ & $0.0 \%$ & $40.0 \%$ & $16.0 \%$ & $56.0 \%$ \\
& Problems at home with people in your family. & $0.0 \%$ & $0.0 \%$ & $0.0 \%$ & $20.0 \%$ & $20.0 \%$ \\
Total & $4.0 \%$ & $0.0 \%$ & $52.0 \%$ & $44.0 \%$ & $100.0 \%$ \\
\hline
\end{tabular}


Table 2. Cont.

\begin{tabular}{ccccccc}
\hline \multirow{2}{*}{ Gender } & \multicolumn{2}{c}{ How Old Are You? } & \multicolumn{2}{c}{ Total } \\
& & $\mathbf{8}$ & $\mathbf{9}$ & $\mathbf{1 0}$ & $\mathbf{1 1}$ & \\
\hline \multirow{3}{*}{ Boy } & Problems with you school work. & $5.0 \%$ & $10.0 \%$ & $10.0 \%$ & $25.0 \%$ & $50.0 \%$ \\
& Problems getting along with other kids. & $0.0 \%$ & $0,0 \%$ & $5.0 \%$ & $5.0 \%$ & $10.0 \%$ \\
& Problems at home with people in your family. & $0.0 \%$ & $5.0 \%$ & $20.0 \%$ & $15.0 \%$ & $40.0 \%$ \\
& Total & $5.0 \%$ & $15.0 \%$ & $35.0 \%$ & $45.0 \%$ & $100.0 \%$ \\
\hline \multirow{3}{*}{ Total } & Problems with you school work. & $4.4 \%$ & $4.4 \%$ & $11.1 \%$ & $15.6 \%$ & $35.6 \%$ \\
& Problems getting along with other kids. & $0.0 \%$ & $0.0 \%$ & $24.4 \%$ & $11.1 \%$ & $35.6 \%$ \\
& Problems at home with people in your family. & $0.0 \%$ & $2.2 \%$ & $8.9 \%$ & $17.8 \%$ & $28.9 \%$ \\
& Total & $4.4 \%$ & $6.7 \%$ & $44.4 \%$ & $44.4 \%$ & $100.0 \%$ \\
\hline
\end{tabular}

In different items, the way that participants face these problems is determined by gender. Those with statistically significant differences are: In the item 'Think about what I could do before I do anything', the answer "Never" corresponds to $8.9 \%$ of the total, both of them (boys and girls) with $4.4 \%$. The answer "A Little" corresponds to $46.7 \%$ of the total percentage; in this case, boys contribute with $11.1 \%$ and girls with $35.6 \%$. In addition, the option 'Quite' was chosen by $22.2 \%$ of the total percentage; specifically, boys with a percentage of $13.3 \%$ and girls $8.9 \%$. Finally, 'A lot' corresponds to $22.2 \%$ of the total; boys contribute with a percentage of $17.8 \%$ and girls $4.4 \%$. With regard to the chi-squared test, we observed that there is a statistically significant association between boys and girls, in the variable under study, and the asymptotic $p$-value (Sig. $=0.022<0.05$ ).

Regarding the symmetrical measures in the item 'Get into a fight with someone', we used the contingency coefficient, which indicates that there is a statistically high and direct proportional association because it is positive and associated in $40.5 \%$.

As Table 3 demonstrates, there is a statistically significant association between boys and girls in the chi-squared test when the children face the problem with the strategy 'Try to put it out of my mind', due to the asymptotic significance value.

Table 3. Differences according to gender in the item 'Try to put it out of my mind'.

\begin{tabular}{cccc}
\hline & Value & Df & Asymptotic Significance (Bilateral) \\
\hline Pearson's chi-squared test & 8.741 & 3 & 0.033 \\
Likelihood ratio & 11.461 & 3 & 0.009 \\
Linear-by-linear Association & 1.170 & 1 & 0.279 \\
N of valid cases & 49 & & \\
\hline
\end{tabular}

Then, the symmetrical measures were analysed in the items 'Worry about all the bad things that could happen' and 'Go somewhere and play'. In the first item, the contingency coefficient indicates that there is a statistically high and direct proportional significant association, associated in $49.9 \%$, (contingency coefficient $=0.389$ y Sig. $=0.001<0.05$ ). However, in the second item, there is a statistically significant association between boys and girls, the asymptotic significance value is (Sig. $=0.006<0.05$ ), and its contingency coefficient is $(0.458 \mathrm{y} \mathrm{Sig.}=0.006<0.05)$. Regarding the effect size, it is higher in the item 'Worry about all the bad things that could happen' and 'Go somewhere and play' $(d=0.208)$.

With regard to the children's coping strategy 'Pretend the problem never happened', there is a statistically significant association between boys and girls in the chi-squared test, regarding the variable under study. The asymptotic significance (Sig. $=0.022<0.05$ ), and the contingency coefficient is $0.409(\mathrm{~d}=0.218)$.

In the item 'Play video games or a hobby', with respect to the symmetric measures table (Table 4), it can be see that there is a high and directly proportional statistically significant association in the contingency coefficient. 
Table 4. Symmetric measurements for the item 'Play video games or a hobby'.

\begin{tabular}{ccc}
\hline & Value & Approximate Statistical Significance \\
\hline Nominal by nominal Contingency coefficient & 0.493 & 0.003 \\
N of valid cases & 44 & \\
\hline
\end{tabular}

In the item 'Try not to think about it', there is a statistically significant association between boys and girls, regarding the variable under study, the significance value is asymptotic in the chi-squared test, and the asymptotic significance value (Sig. $=0.030<0.05$ ) is less than $5 \%$ level of significance. As for the symmetric measures, the contingency coefficient indicates that there is a high statistically significant association and it is directly proportional because it is positive and is associated at $41.1 \%$ (contingency coefficient $=0.411$ ).

In the item 'Get scared that something bad might happen to me' the asymptotic significance value is 0.046 and the contingency coefficient is 0.392 in the chi-squared test.

The highest correlation of all is 'Try very hard to forget about it', with a contingency coefficient of 0.551 and Sig. $=0.000$.

In addition, there are two items, in which there are significant differences 'I don't do anything' and 'Yell to let my feelings'. Regarding effect sizes in these mentioned items, they are between low and moderate $(\mathrm{d}=0.358 ; \mathrm{d}=0.151$, respectively).

Table 5 shows the results for the first item, while Table 6 shows the results for the second item.

Table 5. Differences according to gender in the item 'I don't do anything'.

\begin{tabular}{cccc}
\hline & Value & Df & Asymptotic Significance (Bilateral) \\
\hline Pearson's chi-squared & 7.986 & 3 & 0.046 \\
Likelihood ratio & 10.691 & 3 & 0.014 \\
Linear-by-linear association & 6.366 & 1 & 0.012 \\
N of valid cases & 43 & & \\
\hline
\end{tabular}

Table 6. Symmetric measurements for the item 'Yell to let my feelings'.

\begin{tabular}{cccc}
\hline & Value & Approximate Significance \\
\hline $\begin{array}{c}\text { Nominal by Nominal } \\
\text { N of valid cases }\end{array}$ & $\begin{array}{c}\text { Contingency coefficient } \\
44\end{array}$ & 0.441 & 0.014 \\
\hline
\end{tabular}

Additionally, the last item for which we found significant differences was: 'Try to think happy thoughts', from which it can be deduced that there is a statistically significant association between boys and girls in the study variable of the chi-squared test, with an asymptotic significance value of 0.003. As for the symmetrical measures, the contingency coefficient is 0.489 .

Finally, we performed the Kolmogorov-Smirnov test for normality to assess whether there are differences between boys and girls with respect to age.

It is observed that the level of significance is $0.031<0.05$; therefore, the hypothesis of normality was rejected. That is, the data of the created variable does not have the normal distribution and therefore, it is necessary to proceed with the non-parametric analysis.

As shown in Table 7 and Figure 1, the Mann-Whitney U test value is Sig. $=0.177>0.05$. Therefore, we can say that there is no equality in dimensions between boys and girls. 
Table 7. Are you girl or boy?

\begin{tabular}{cc}
\hline Total N & 49 \\
\hline Mann-Whitney U test & 367.500 \\
\hline Wilcoxon-W & 667.500 \\
\hline Contrast statistic & 367.500 \\
\hline Standard error & 49.981 \\
\hline Standardized contrast statistic & 1.351 \\
\hline Asymptotic significance (bilateral test) & 0.177 \\
\hline
\end{tabular}

Are you girl or boy?

Girl Boy

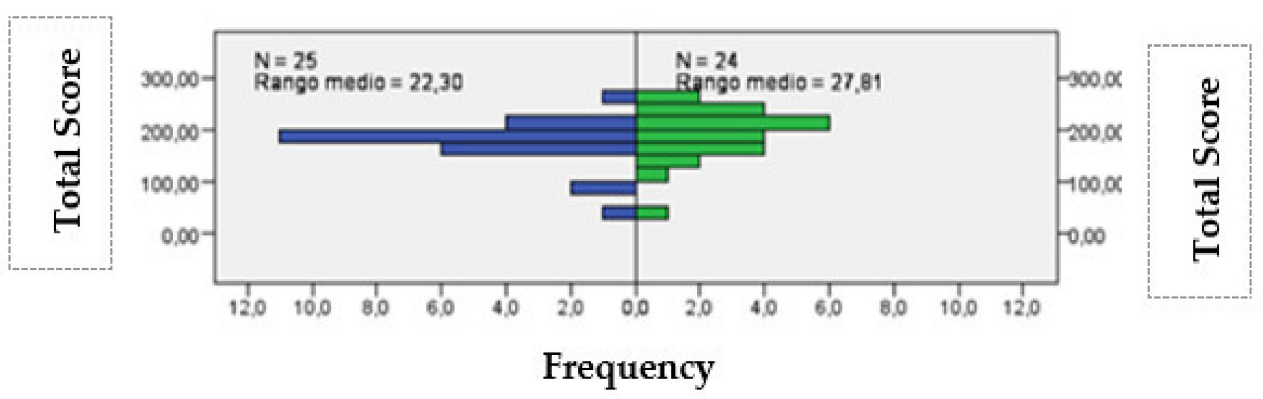

Figure 1. Mann-Whitney U test for independent samples.

In the Kruskal-Wallis test, we can see that the value of Sig. $=0.019<0.05$ (Table 8 and Figure 2). Therefore, we could say that there are significant differences in the opinions according to the age of boys and girls.

Table 8. How old are you?

\begin{tabular}{cc}
\hline Total N & 49 \\
\hline Contrast statistic & 9.924 \\
\hline Degrees of freedom & 3 \\
\hline Asymptotic significance (bilateral test) & 0.019 \\
\hline
\end{tabular}

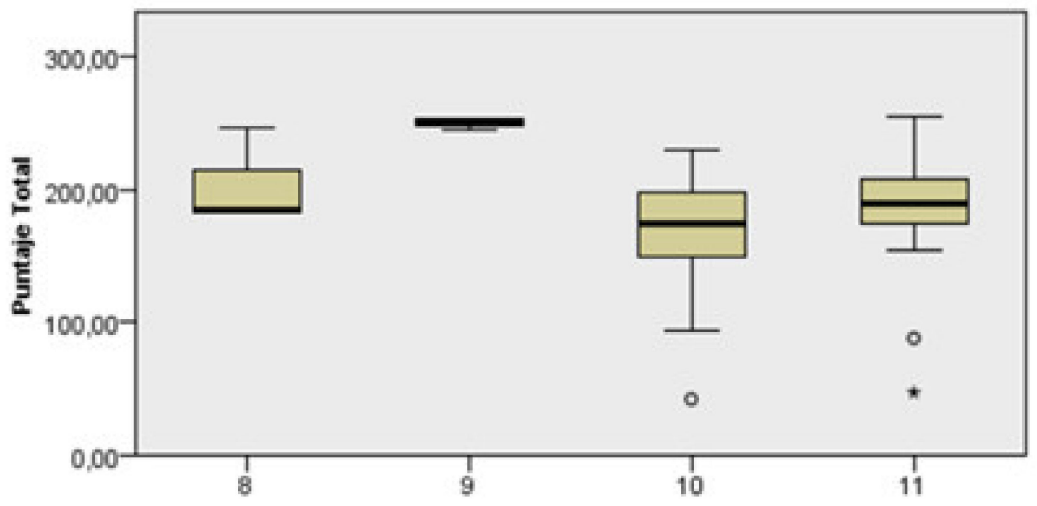

Figure 2. Kruskal-Wallis test for independent samples. 


\section{Discussion}

This current study investigated children's coping strategies used when faced with different problems in their daily life (problems with their school-work, problems getting along with other kids and problems at home with people in their family) in a vulnerable social environment. We found this research very significant in evaluating the coping responses of early years students in vulnerable contexts where the levels of stress and difficulties are more entrenched in the development of the child's personality [23]. As Connor-Smith and Flachsbart [9] affirm, a better understanding of the role of personality in the coping process requires the evaluation of personality, specific coping strategies and other aspects.

The results show that there are gender differences in the way in which children deal with problems. These results have been seen in other investigations [24] in which specific forms of coping depend on gender. In addition, the Kackar et al. [25] investigations show that gender differences are also seen in the need for support and a 'problem solving strategy': it is higher in girls and, nevertheless, boys they have a higher percentage of avoidant coping. Additionally, as mentioned in [8], there were gender differences in coping, symptoms, and emotions in adolescents. In this way, the research of Skinner and Zimmer-Gembeck [26] found a different perception of age and gender in the development of children's school work. Thus, it can be seen in our study that this difficulty increases with age. In the case of coping with bullying, victimized girls are more communicative and more often seek emotional support and problem-solving advice [27].

Sometimes, young people seem passive, indifferent and do not take any preventive measures when they are faced with some problems. In this situation, the common motives for disengagement are minimization, mistrust, acceptance of the situation [26] Moreover, children with social anxiety are likely to promote or inhibit particular ways of coping with stressors, due to the fact that conditions like depression and social anxiety involve different forms of social information-processing [28].

The findings of our study highlight the importance of the need for children to learn coping strategies for decision making and problem-solving from an early-years stage; in this way, they also learn positive and negative emotions in a socially appropriate way. Besides gender and age, previous experiences with stress, personality and social context also play a role in children's coping preferences; for example, when a child is faced with a stressful event, such as a conflict between peers, different emotions lead to different types of answer. Therefore, strong relationships with peers and parents play a decisive role in the endorsement of high-engagement coping strategies.

This study need to continue analysing coping strategies as a predictor of different behaviours and actions in controlled boys and girls as these strategies are essential for their personal and social development; as previously noted [27], coping strategies have a great potential to help someone in their daily life. These strategies are even more necessary in contexts of vulnerability and disease [18,29-31].

\section{Conclusions}

The current study investigated the coping strategies children use when faced with different stressors in their daily life. This study indicated that most children were upset by problems in getting along with other children.

In conclusion of this study, we showed that coping strategies reflect the repertoire of answers to stress that children in a vulnerable context have. In this case, when children are faced with problems like getting along with other children, they think a little about what they can do before doing something; both girls and boys face the problem with the strategy of trying to put it out of their mind and trying not to think about it and trying to think happy thoughts.

Finally, there is a high and proportional association with problems in getting along with other children and getting into a fight with someone, worrying about all the bad things that could happen, and pretending the problem never happened.

As we said before, it is very important that children learn different coping strategies to deal with different problems at an early age for their personal and social development. Indeed, limited 
coping and high passivity are associated at all ages with a risk of depression and other internalized symptomatology [32].

Therefore, this research leads us to the main conclusion that coping strategies are a great tool to help children from an early age in vulnerable contexts.

Author Contributions: E.M.M.-J. translated the questionnaire into Spanish. M.d.C.L.-B. collected the data. C.S.-R. and I.M.-S. conducted the statistical analyses and interpreted the results. C.S.-R. and E.M.M.-J. wrote and reviewed the manuscript. I.M.-S. critically reviewed the manuscript. All authors have read and agreed to the published version of the manuscript.

Funding: This research received no external funding.

Conflicts of Interest: The authors declare no conflict of interest.

\section{References}

1. Wood, S.; Bhatnagar, S. Resilience to the effects of social stress: Evidence from clinical and preclinical studies on the role of coping strategies. Neurobiol. Stress 2015, 1, 164-173. [CrossRef]

2. Hamilton, K. Low-income Families and Coping through Brands: Inclusion or Stigma? Sociology 2011, 46, 74-90. [CrossRef]

3. Kliewer, W.; Parrish, K.A.; Taylor, K.W.; Jackson, K.; Walker, J.M.; Shivy, V.A. Socialization of Coping with Community Violence: Influences of Caregiver Coaching, Modeling, and Family Context. Child Dev. 2006, 77, 605-623. [CrossRef]

4. Nicolotti, L.; El-Sheikh, M.; Whitson, S.M. Children's coping with marital conflict and their adjustment and physical health: Vulnerability and protective functions. J. Fam. Psychol. 2003, 17, 315-326. [CrossRef] [PubMed]

5. E Gray, D. Ten years on: A longitudinal study of families of children with autism. J. Intellect. Dev. Disabil. 2002, 27, 215-222. [CrossRef]

6. Mancil, G.R.; Boyd, B.A.; Bedesem, P. Parental stress and autism: Are there useful coping strategies? Educ. Train. Dev. Disabil. 2009, 44, 523-527.

7. Lopes, V.; Clifford, T.; Minnes, P.; Ouellette-Kuntz, H. Parental stress and coping in families of children with and without developmental delays. J. Dev. Disabil. 2008, 14, 99.

8. Zimmer-Gembeck, M.J.; Skinner, E.A. Review: The development of coping across childhood and adolescence: An integrative review and critique of research. Int. J. Behav. Dev. 2010, 35, 1-17. [CrossRef]

9. Connor-Smith, J.K.; Flachsbart, C. Relations between personality and coping: A meta-analysis. J. Pers. Soc. Psychol. 2007, 93, 1080-1107. [CrossRef]

10. Compas, B.E.; Connor-Smith, J.K.; Saltzman, H.; Thomsen, A.H.; Wadsworth, M.E. Coping with stress during childhood and adolescence: Problems, progress, and potential in theory and research. Psychol. Bull. 2001, 127, 87-127. [CrossRef]

11. Phelps, C.E.R. Children's responses to overt and relational aggression. J. Clin. Child Adolesc. Psychol. 2001, 30, 240-252. [CrossRef]

12. Tenenbaum, L.S.; Varjas, K.; Meyers, J.; Parris, L. Coping strategies and perceived effectiveness in fourth through eighth grade victims of bullying. Sch. Psychol. Int. 2011, 32, 263-287. [CrossRef]

13. Waasdorp, T.E.; Bradshaw, C.P. Examining student responses to frequent bullying: A latent class approach. J. Educ. Psychol. 2011, 103, 336-352. [CrossRef]

14. Cicchetti, D.; Rogosch, F.A. Adaptive coping under conditions of extreme stress: Multilevel influences on the determinants of resilience in maltreated children. New Dir. Child Adolesc. Dev. 2009, 2009, 47-59. [CrossRef] [PubMed]

15. Blount, R.L.; Davis, N.; Powers, S.W.; Roberts, M.C. The influence of environmental factors and coping style on children's coping and distress. Clin. Psychol. Rev. 1991, 11, 93-116. [CrossRef]

16. di Minci, M.C.R. Evaluación del afrontamiento en niños de 8 a 12 años (Coping assessment in 8 to 12 year-old-children). Rev. Mex. Psicol. 2006, 23, 196-201.

17. Skinner, E.A.; Edge, K.; Altman, J.; Sherwood, H. Searching for the structure of coping: A review and critique of category systems for classifying ways of coping. Psychol. Bull. 2003, 129, 216-269. [CrossRef] 
18. García, J.L.; González, M.A.; Ballesteros, B. Unidad Didáctica de Pedagogía: Introducción a la Investigación en Educación; Universidad Nacional de Educación a Distancia: Madrid, Spain, 2001.

19. Ruiz, M.A.; Pardo, A.; San Martín, R. Modelos de ecuaciones estructurales. Pap. Psicól. 2010, 31, 34-45.

20. Compas, B.E.; Malcarne, V.L.; Fondacaro, K.M. Coping with stressful events in older children and young adolescents. J. Consult. Clin. Psychol. 1988, 56, 405-411. [CrossRef]

21. Hampel, P.; Petermann, F. Age and Gender Effects on Coping in Children and Adolescents. J. Youth Adolesc. 2005, 34, 73-83. [CrossRef]

22. Fedorowicz, A.E. Children's Coping Questionnaire (CCQ): Development and Factor Structure. Ph.D. Thesis, University of Manitoba, Winnipeg, MB, Canada, 28 November 1995. Available online: http://summit.sfu.ca/ system/files/iritems1/6875/b1774989x.pdf (accessed on 29 May 2020).

23. Dee, R. Coping Strategies. In Voices of Experience: Narratives of Mental Health Survivors; John Wiley \& Sons: Hoboken, NJ, USA, 2010. [CrossRef]

24. D’Haenens, L.; Vandoninck, S.; Donoso, V. How to Cope and Build Online Resilience? EU Kids Online Network: London, UK, 2013.

25. Kackar, H.Z.; Shumow, L.; Schmidt, J.A.; Grzetich, J. Age and gender differences in adolescents' homework experiences. J. Appl. Dev. Psychol. 2011, 32, 70-77. [CrossRef]

26. Skinner, E.A.; Zimmer-Gembeck, M.J. The Development of Coping. Annu. Rev. Psychol. 2007, 58, 119-144. [CrossRef] [PubMed]

27. Banerjee, R.A. Social Cognition and Anxiety in Children. In Social Cognition and Developmental Psychopathology; Sharp, C., Fonagy, P., Goodyer, I., Eds.; Oxford University Press: Oxford, UK, 2008; pp. 239-269.

28. Eschenbeck, H.; Kohlmann, C.-W.; Lohaus, A. Gender Differences in Coping Strategies in Children and Adolescents. J. Individ. Differ. 2007, 28, 18-26. [CrossRef]

29. Kochenderfer-Ladd, B.; Skinner, K. Children's coping strategies: Moderators of the effects of peer victimization? Dev. Psychol. 2002, 38, 267-278. [CrossRef]

30. De Boo, G.M.; Wicherts, J.M. Assessing Cognitive and Behavioral Coping Strategies in Children. Cogn. Ther. Res. 2007, 33, 1-20. [CrossRef]

31. Hastings, R.P.; Kovshoff, H.; Brown, T.; Ward, N.J.; Degli Espinosa, F.; Remington, B. Coping strategies in mothers and fathers of preschool and school-age children with autism. Autism 2005, 9, 377-391. [CrossRef]

32. Mudarra-Sánchez, M.J.; Sánchez-Romero, C. Coping and resilience strategies in early care for the welfare of families. In Early Care Practices Focused on Family and Natural Settings; Escorcia, C.Y., Rodríguez, L., Eds.; UNED: Madrid, Spain, 2019; pp. 339-370. 